'Under the Mediterranean' The Honor Frost Foundation Conference on Mediterranean Maritime Archaeology 20th $-23_{\text {rd }}$ October 2017 Short Report Series.

doi: https://doi.org/10.33583/utm2020.06

(C) 2020 The Author

\title{
The tradition of fishery and fishing gear in the island of Cyprus (18th and 19th centuries AD)
}

\section{K. Mavromichalou ${ }^{\mathrm{a}}$, M.M. Michael ${ }^{\mathrm{b}}$}

aLibrarian CAARI, librarian@caari.org.cy

bPhD Candidate (HFF Studentship), University of Southampton, m.m.michael@ soton.ac.uk

Cyprus is an island in the Mediterranean Sea. Consequently, it is expected that Cypriots are good fishermen and fishing activities are part of their daily lives through the time. However, folk verses and historical evidence dated to the 18th and 19th centuries AD present a different view. Based on this data, fishing was an occasional activity, because the amount of fish in Cypriot waters was small. This research attempts to analyse this evidence and to reveal that fishing was an essential part of the daily life of Cypriots during 18th and 19th centuries.

\section{Key words}

Cyprus, Fishery, Fishing Gear, Mediterranean, 18th century, 19th century.

Based on various fish remains and finds, it is obvious that inhabitants of Cyprus explored and managed the sea for millennia. However, fishing activities seem to be limited during the modern periods of Cypriot history. Consequently, the main aim of this research is to combine the historical testimonies, the oral tradition and the results of an ethnographical study in an attempt to acquire a better general understanding of the formative phases of fisheries in the island during the recent periods of its history (18th and 19th centuries). Additionally, it will attempt to examine and reconstruct the development of fishing technology and methods. 


\section{Methodology}

To complete this research, iconographical evidence was studied, in order to understand the development of fishing equipment and to interpret and describe the traditional fishing practices. Historical sources and testimonies were also considered as they can provide useful information about the fishing technology, the fishing activities and their role in the daily life of the population of the island. Furthermore, some local fishermen were interviewed, in order to collect information about the fishing technologies, the difficulties of fishing activities and generally about their experience.

\section{Fishing in the daily life of the island through testimonies, historical and iconographical sources}

Although fish are commonly represented in ancient Cypriot art and large numbers of fish remains and marine shells are commonly found during excavations, some scholars mentioned that the island is not particularly rich in sea-life, and fish were practically unknown to people living far from the coast (Egoumenidou and Michaelides, 2000; Ionas, 2001). They stated that fishing was an occasional activity, which Cypriots only developed when there was a general failure of crops and a devastation of domesticated stock. Ionas (2001: 217) specifically mentions that the small amount of fish in Cypriot waters, the lack of methods for the preservation of fish, and the limited fishing methods illustrated that the profession of fisherman was difficult and not so lucrative during the most recent periods of Cypriot history.

According to folk verses, it seems that the aforementioned opinion is true (Egoumenidou and Michaelides,

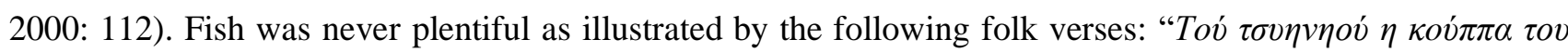

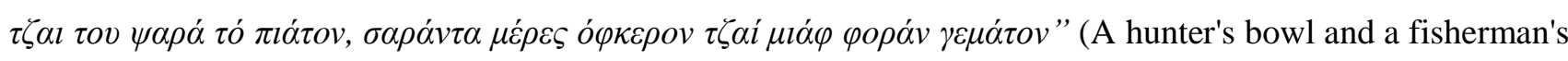
plate are forty times empty and only one day full).

Furthermore, Ohnefalsch-Richter (1913: 152) mentions that Cypriots did not engage with fishing activities, although the sea was suitable for fishing. Her opinion is supported by the Consular Report of 1859, where which reads "Le poisson est tres-abondant mais il y a peu de pecheurs" (Papadopoulos, 1980: 38). Furthermore, Dr J. Sibthorp (Cobham, 1908: 334) who visited Cyprus in 1787 and collected notes about the natural history of the island, mentions, "the shores of Cyprus receive a great number of Mediterranean fishes". In conclusion, it seems that the amount of fish in the Cypriot waters was not limited.

Regarding the recent studies, around 300 fish species have been recorded in the sea around Cyprus (Ioannou and Michaelides, 2016). The results of these studies probably reveal that the Cypriot seabed was not poor in sea-life. Consequently, the amount of fish in the Cypriot waters was not the reason for the limited development of fishing activities, but probably few inhabitants of the island preferred to be involved with fishing, due to it being a difficult profession. 
However, there is surviving evidence from the 18 th century, when pilgrims and travellers passing through the island left accounts of the people and their eating habits. This evidence proves that fish was not unknown to Cypriots and fishing activity was part of their daily life.

Drummond (Cobham, 1908: 302), writing in 1750 and describing a small harbour near Ayia Napa, gives more details on fishing: “... the poor people employ themselves in fishing, with boats of a very particular texture, consisting of a few sticks bound together, with some very small ones laid in the hollow where the fisherman sits managing his tackle, and steering his machine with a paddle". Based on this testimony, a piece of information about the fishing gear that fishermen used is revealed. Moreover, fishing was probably a profession of people of lower social status.

Fish also has an essential place in the Cypriot diet till today, as there are plentiful ways to cook it. Based on testimonies of an oral tradition, fish were roasted in hot ashes, fried in olive oil, boiled, marinated, cooked in earthen pots with oil and onions, or baked in the oven with tomatoes, onions and parsley (Egoumenidou and Michaelides, 2000: 115). Some of them, such as eels, were also preserved using salting and smoking, while some others, such as crabs and shells were consumed uncooked with a squeeze of lemon.

\section{Fish species in Cypriot waters}

According to the aforementioned data, many species of fish seem to exist in Cypriot waters. Dr J. Sibthorp (Cobham, 1908: 334, 338), who visited Cyprus in 1787, mentions that there were abundant kinds of Grecian fish. He specifically mentions that "the striking agreement of the modern Greek names of fish with those of

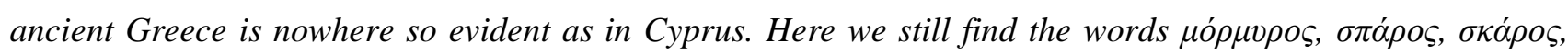

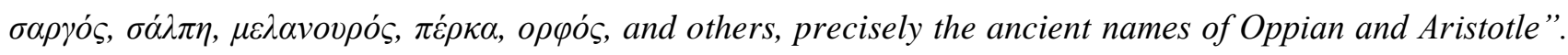
$\mathrm{He}$ also referred to some specific species that were found in Cyprus (Cobham, 1908: 338): raia torpedo

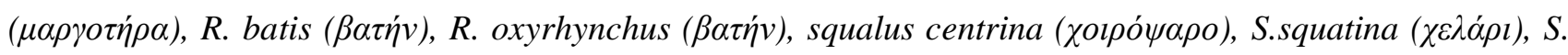

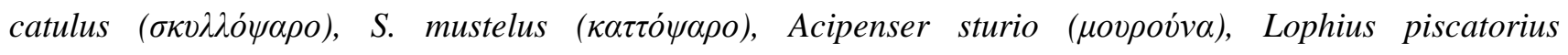
( $\beta \omega \theta \rho \alpha \kappa o ́ \psi \alpha \rho o)$, Sygnathus hippocampus ( $\alpha \pi \pi \alpha \rho o ́ \psi \alpha \rho o v)$, Murena Anguilla ( $\alpha \chi \dot{\lambda} \imath v)$ and several species of Labrus and Sparus.

According to the results of an ethnographical study, some of the fish that can be caught in Cypriot waters are:

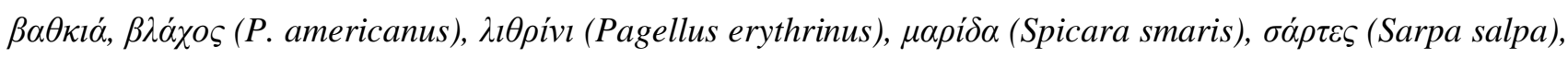

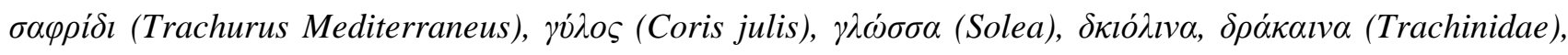

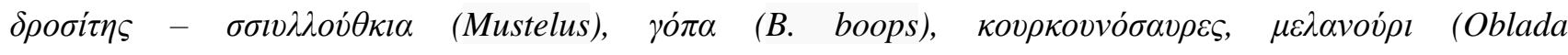

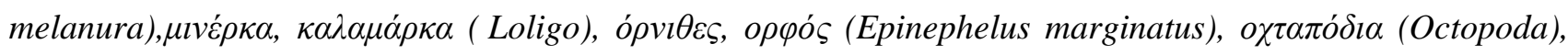

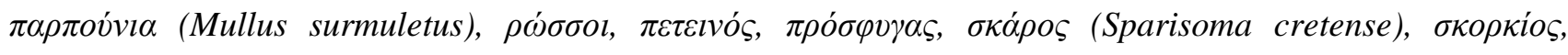

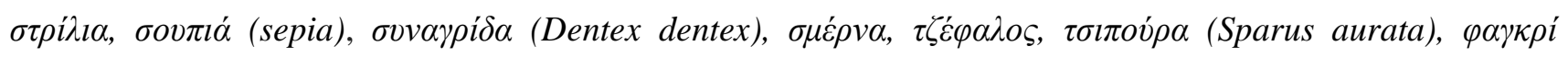

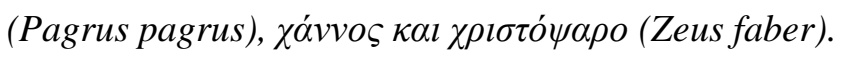


On the other hand, there is not enough information about the existence of river fish. The main reason for the absence of river fish is probably the fact that there are mainly rivulets in Cyprus. The rivulets generally dry up during summer; as a result, river fish cannot survive. However, Dr J. Sibthorp (Cobham, 1908: 334) stated that "the eel (Anguilla anguilla) was their only inhabitant".

Furthermore, Richard Pococke, who visited Cyprus for two months in 1738, gave some information about river fish in Chapter XI of his third book, which is about the natural history, natives, customs, trade and government of Cyprus. He described that "the ancients mention three rivers in Cyprus, the Lycus, Tetius and Pedius, through at the best they deserve only the name of rivulets, and I suppose the water seldom fails in these, though it is generally said that there are no rivers in Cyprus: It is certain they have no fresh water fish, except small crabs, which are in most of the rivers in Asia" (Cobham, 1908: 266).

Finally, small shells are also plentiful and are commonly found on ancient sites, while remnants of sea urchins and crabs are commonly found on ancient sites, and presumably continued to be eaten through the ages (Egoumenidou and Michaelides, 2000; Michaelides, 1998: 26-29).

\section{Fishing Methods}

Several methods were used for catching fish, many of them common everywhere in the Mediterranean. The most important equipment was a boat, chiefly with a mast, a sail, a steering mechanism, and an anchor. Inside the boat, there were usually buoys, weights used for calculating the depth, hooks, nets and net weights, harpoons used for catching the larger fish, fishing rods, baskets used for collecting, cleaning and preserving the fish and lamps, which were used during night fishing.

Some specific methods used for catching fish from a boat are:

\section{Fishing nets}

Fishing using nets started in the afternoon or at evening (Iona, 2001: $220-222$ ). Fishermen chose the right location, where they can find a lot of fish, and they slowly released the nets with two buoys. They left nets overnight and in the early morning they collected them. Then, they took fish from the nets and they divided them in the baskets, according to their species, size or quality. This scene is presented in one painting of Michael Kassialos, who was a Cypriot painter working at the end of the $19_{\text {th }}$ century and beginning of the $20_{\text {th }}$ century (Assia, 2009).

\section{Fishing line}

Fishing line is a cord used or made for angling (Iona, 2001: 222-223). It was a cord, on which small and large hooks are tied at regular intervals. The small hooks were used for catching small or medium size fish and the large hooks for bigger fish. Bait was placed on the hooks, in order to attract the fish.

\section{Fishing with skarka}


An unusual method is using the skarka, which is not only found in Cyprus, but in many places in the eastern Mediterranean (Ionas, 2001: 223-224; Papademetriou, 1993: 75). It was a round basket with a hole in the middle, which was used as a fish trap. There were different sizes and different thicknesses of weave, in order to catch different kinds of fish. They were traditionally made with thin branches of myrtle, although metal wire predominates in more recent years. The skarka was half-filled with leaves of different plants then dropped in the sea, mainly next to bushes, and a few hours later, fishermen collected it full of fish.

\section{Fishing using an iron rod}

Another method, employed until recently, was using an iron rod, $2-2.5 \mathrm{~m}$ long, fitted with a series of three fishhooks, which were masked behind a white handkerchief (Egoumenidou and Michaelides, 2000: 113). This method was mainly used to fish octopus, which, attracted by the white cloth, became unwittingly attached to the hidden hooks.

Finally, there were other methods for fishing in shallow waters or from the coast. Some of them were fishing rods, three- or four-pronged forks, basket/traps placed in narrow passages or wooden tongs fitted with nails, which were the most efficient methods for catching eel. Sometimes, fishermen used a poisonous plant, in order to anaesthetize fish and catch them more easily. This method is presented on a painting of Michael Kkasialos (Assia, 2009), where many men holding rods and shovels wait for the poisoned eels, in order to catch them.

\section{Conclusions}

According to this brief research, it is obvious that fishing was a part of the daily life of Cypriots during the 18 th and 19th centuries. However, fishing was not a profession that many Cypriots chose. The reason was not the lack of fish in the Cypriot waters, but fishing was probably a difficult and dangerous occupation. Regarding the testimonies, fishing was probably an activity for poor people.

Moreover, fish was known to them and had an essential place in the Cypriot diet, as there were many different ways of cooking them. Some of these cooking skills were still known in recent years. Furthermore, many of the fishing methods are still used by fishermen today. Nets and skarka are some of the techniques that professional and amateur fishermen used in more recent years.

In conclusion, it is obvious that fishing is an activity that influenced the daily life of Cypriots throughout the different chronological periods, but the techniques have changed very little. However, much more research needs to be done, and this is the main purpose that an on-going $\mathrm{PhD}$ thesis strives to accomplish.

\section{Acknowledgements}

We would like to express our gratitude to the organizers for allowing us to participate in this well-organised conference. We are also grateful to the Honor Frost Foundation and Dr Lucy Blue for their endless support. 
Final thoughts go to reviewers, supervisors, friends and colleagues as this publication would not have been completed without their guidelines and help.

\section{Reference list}

Assia.org, 2009, online source: www.assia.org.cy.

Cobham, C.D., 1908, Excerpta Cypria. Materials for a history of Cyprus. London: Cambridge University Press.

Egoumenidou, E. and Michaelides, D., 2000, Gathering, hunting, fishing. The procurement of food from the non-domesticated animal kingdom in Cyprus through the ages, in P. Lysaght (ed.), Food from Nature. Attitudes, Strategies and Culinary Practices. Proceedings of the 12th conference of the International Commission for Ethnological Food Research, Umea and Frostviken, Sweden, 8 - 14 June 1998, 111-120 Uppsala: The Royal Gustavus Adolphus Academy for Swedish Folk Culture.

Ioannou, G. and Michaelides, N., 2016, The 100 important fish species of Cypriot sea. Nicosia: Press and Information Office for the Department of fisheries and Marine Research.

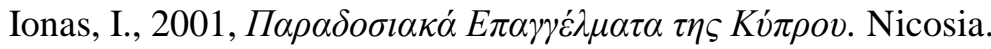

Michaelides, D., 1998, Food in Ancient Cyprus, in P. Lysaght (ed.), Food and the Traveller. Migration, Immigration, Tourism and Ethnic Food. Proceedings of the 11 th Conference of the International Commission for Ethnological Food Research, Cyprus, June 8-14, 1996, 22-43. Nicosia.

Papademetriou, E., 1993, Cyprus Folk Art. Nicosia: Cultural Services, Ministry of Education \& Culture.

Papadopoulos, Th. (ed.), 1980, Consular Reports of the 19th century. Nicosia. 